\title{
PKM Kelompok Pemilah Sampah TPSA Bulusan Kabupaten Banyuwangi melalui Program Ompimpah
}

\author{
Alfin Hidayat ${ }^{\# 1}$, Subono ${ }^{* 2}$, Mohamad Dimyati Ayatullah ${ }^{\# 3}$ \\ Afif Syarifuddin Maulana $^{\# 4}$, Khusnul Khotimah ${ }^{* 5}$, Biyanti Milasari ${ }^{\# 6}$ \\ Dimas Gusti Maulana $^{\# 7}$, Ana Putri Utami ${ }^{* 8}$, Yusuf Nur Fauzi ${ }^{\# 9}$ \\ Nur Alvi Nazimah ${ }^{\# 10}$, Muhammad Faisol Amin ${ }^{* 11}$, Mohamad Maskur Hadi ${ }^{\# 12}$ \\ Nina Dyah Ayu Ningrum ${ }^{\# 13}$ \\ ${ }^{\#}$ Jurusan Teknik Informatikka, Politeknik Negeri Banyuwangi, Banyuwangi ${ }^{\# 1-13}$ \\ lalfin.hidayatepoliwangi.ac.id \\ ${ }^{2}$ subonoepoliwangi.ac.id \\ 3 ayt.dimyati@gmail.com \\ ${ }^{4}$ afif.mbppoliwangiegmail.com \\ ${ }^{5}$ khusnulkhotimah.ti9.poliwangiegmail.com \\ ${ }^{6}$ biyantimilasari.ti9.poliwangiegmail.com \\ 7 dimasafan13egmail.com \\ 8 anaputriutami@gmail.com \\ 9nurf84925@gmail.com \\ ${ }^{10}$ nazimahalvilyahoo.com \\ ${ }^{11}$ mohfaisolamin.ti9.poliwangiegmail.com \\ ${ }^{12}$ mohamadmaskurhadi.ti9.poliwangi@gmail.com \\ ${ }^{13}$ dyahnina18@gmail.com
}

\begin{abstract}
Pada kelurahan Bulusan terdapat Tempat Pembuangan Sampah Akhir (TPSA) yang menampung beberapa tempat pembuangan sampah dari berbagai TPSS di Kabupaten Banyuwangi. Volume sampah yang masuk setiap harinya kurang lebih mencapai 122,5 meter ${ }^{3}$ atau setara dengan 27 rit/truk. Sampah yang ditampung di TPSA Bulusan berupa sampah padat seperti plastik, botol bekas minuman, hingga sisa sayuran. Keadaan sampah di TPSA bulusan seperti timbunan besar yang menggunung tinggi setiap harinya. Meskipun pemilah sampah yang setiap harinya memiliah sampah tetap tidak mengurangi banyaknya sampah. Berdasarkan hal tersebut, diperlukan suatu upaya untuk menggerakkan masyarakat guna mengoptimalkan pengolahan sampahdari jenis sampah anorganik agar dapat dimanfaatkan menjadi barang yang bernilai. Melalui program Optimalisasi Pengolahan Sampah Menjadi bentuk Paving (Ompimpah), tim pengabdian masyarakat Politeknik Negeri Banyuwangi berupaya untuk mengurangi volume sampah terutama sampah plastik di area TPSA Bulusan
\end{abstract}


Kabupaten Banyuwangi. Hasilnya dengan adanya program ini, sebanyak $60 \%$ masyarakat sasaran, yaitu kelompok pemilah sampah menjadikan program ompimpah sebagai peluang usaha yang menjanjikan untuk dilakukan secara mandiri.

Keywords - TPSA Bulusan, Program Ompimpah, Sampah Plastik

\section{Pendahuluan}

Sampah adalah buangan yang dihasilkan dari suatu proses produksi baik industri, domestik maupun rumah tangga. Sementara didalam UU No 18 tahun 2008 tentang pengelolaan sampah, disebutkan sampah adalah sisa kegiatan sehari-hari manusia atau proses alam yang berbentuk padat atau semi padat berupa zat organik yang bersifat dapat terurai atau tidak dapat terurai dan dianggap sudah tidak berguna lagi dan dibuang ke lingkungan. Berdasarkan asalnya sampah padat dapat digolongkan menjadi dua yaitu sampah organik dan sampah anorganik. Sampah organik adalah sampah yang dihasilkan dari bahanbahan hayati yang dapat didegradasi oleh mikroba atau bersifat biodegradable, sampah ini dapat terurai melalui proses alami. Sampah anorganik adalah sampah yang dihasilkan dari bahan nonhayati, baik berupa produk sintetik maupun hasil proses pengolahan bahan tambang, sampah ini tidak dapat terurai melalui proses alami.

Pada Kelurahan Bulusan terdapat Tempat Pembuangan Sampah Akhir (TPSA) dari wilayah Kabupaten Banyuwangi. Tempat Pembuangan Sampah Akhir (TPSA) adalah tempat untuk menimbun sampah dan bentuk terakhir perlakuan sampah. Sampah berasal dari Tempat Pembuangan Sampah Sementara (TPSS) yang berada di berbagai wilayah Banyuwangi. Volume sampah yang masuk setiap harinya 122,5 meter $^{3}$ atau 27 rit/truck (Pengawas TPSA, Khairul Anam). Sampah yang dibuang di TPSA Bulusan berupa sampah padat seperti: plastik, botol bekas minuman, sisa sayuran. Menurut Indonesia Solid Waste Association (InSWA), sebagaimana dikutip dari Antara, produksi sampah plastik Indonesia sekitar 5,4 juta ton/tahun. Tak heran jika yang mendominasi sampah di Kelurahan Bulusan merupakan sampah plastik. Di TPSA Bulusan keadaan sampah seperti gunung besar dan tinggi. Timbunan sampah tersebut setiap harinya semakin besar dan tinggi. Meskipun di sana terdapat para pemulung atau pemilah sampah yang setiap harinya mencari sampah tersebut, tetapi tidak mengurangi banyaknya sampah yang ada di sana.

Berdasarkan hal tersebut, diperlukan suatu upaya untuk menggerakkan masyarakat guna mengoptimalkan pengolahan sampahdari jenis sampah anorganik agar seluruh masyarakat dapat memanfaatkan sampah yang ada menjadi sesuatu yang lebih bernilai. Pemilihan sampah anorganik karena jenis sampah ini sulit terurai dengan proses alami sehingga diperlukan pengolahan atau daur ulang agar sampah tersebut bermanfaat. Sampah plastik digunakan untuk bahan dasar membuat paving Di TPSA Bulusan Kabupaten Banyuwangi masyarakat sekitar serta pemilah sampah dapat mengurangi volume sampah yang ada di TPSA Bulusan, juga agar memberikan pengetahuan dan pengalaman kepada masyarakat untuk mengolah sampah menjadi barang berguna seperti paving dan kerajinan tangan yang nantinya bisa mereka jual untuk menambah penghasilan. Sehingga dapat meningkatkan perekonomian masyarakat pemilah sampah agar lebih sejahtera.

\section{PERMASALAHAN MITRA}

Hasil evaluasi yang dilakukan oleh lembaga peneilitian dan pengabdian kepada masyarakat Politeknik Negeri Banyuwangi kepada Mitra diketahui bahwa beberapa permasalahan yang dihadapi yaitu keterbatasan pengetahuan pengolahan sampah plastik:

a. Keterbatasan pengetahuan pengelolaan sampah

Keterbatasan pengetahuan teknologi pengelolaan sampah terutama sampah anorganik menyebabkan proses pengolahan sampah yang dilakukan oleh Mitra membutuhkan waktu lama.

b. Manajemen pengelolaan sampah

Dalam penerapan teknologi yang diterapkan kepada kedua mitra diharapkan manajemen pengelolaan sampah lebih rapi dan tertata melalui pembuatan dan penerapan prosedur kerja manajemen pengelolaan sampah pada setiap proses kegiatan yang dilakukan.

\section{SOLUSI DAN TARGET LUARAN}

\subsection{Solusi}


Berdasarkan permasalahan yang dihadapi oleh Mitra, solusi yang dilakukan untuk meningkatkan usaha mitra adalah:

1.Penerapan teknologi pembuatan plastik menjadi pavingberbahan dasar dari plastik yang dikembangkan oleh lembapa pusat penelitian dan pengabdian kepada masyarakat (PPPM) Politeknik Negeri Banyuwangi.

2. Penerapan manajemen pengelolaan sampah dan keuangan pada Mitra sehingga dapat meningkatkan kuantitas produksi dan berpotensi menjadi pendapatan Mitra.

\subsection{Target Luaran}

Berdasarkan solusi yang ditawarkan, target luaran yang diharapkan adalah:

1. Diharapkan dengan penerapan teknologi tepat guna yang lebih modern dapat meningkatkan ekonomi Mitra dan kerjasama berkelanjutan dengan lembaga Politeknik Negeri Banyuwangi.

2. Diharapkan setelah diimplementasikannya model manajemen pengelolaan sampah dapat menjadi sentra usaha baru yang menjanjikan pada Mitra.

3. Meningkatkan pengetahuan dan pemahaman kepada masyarakat pemilah sampah untuk mengelola dan mengolah sampah menjadi bentuk paving.

4. Terciptanya program kegiatan Ompimpah yang bertujuan meningkatkan perekonomian masyarakat pemilah sampah.

\section{PELAKSANAAN KEGIATAN}

\subsection{Tahapan Pelaksanaan}

Gambaran umum tentang kegiatan pengabdian kepada masyarakat melalui program Ompimpah ditunjukkan pada Gambar 1.

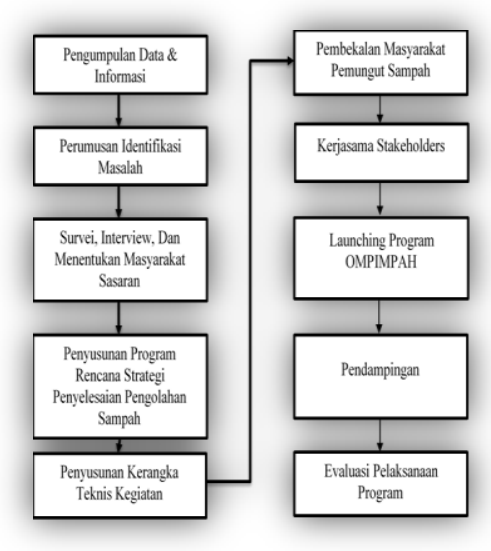

Gambar 1. Tahapan Pelaksanaan Kegiatan PKM

\subsection{Tahapan dalan Menyelesaikan Masalah}

Hal-hal yang dilakukan dalam menyelesaikan masalah khususnya masalah sampah plastik di TPSA Bulusan adalah sebagai berikut:

1. Observasi dan Wawancara kepada Masyarakat

Observasi dilakukan dengan pengamatan langsung dan wawancara langsung dengan Kepala Desa Bulusan untuk mendapatkan data informasi potret kelurahan Bulusan yang lebih akurat. Gambar 2 dan Gambar 3 menunjukkan dokumentasi kegiatan observasi dan wawancara dengan kepala Desa Bulusan dan Ketua RT kelurahan Bulusan.

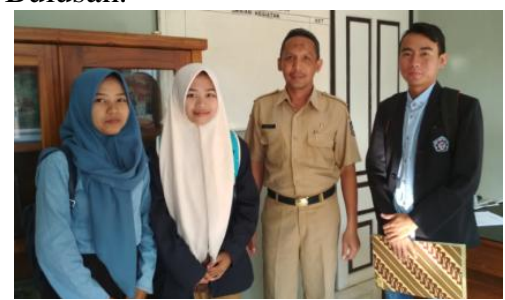

Gambar 2.Observasi dan Wawancara dengan Kepala Desa

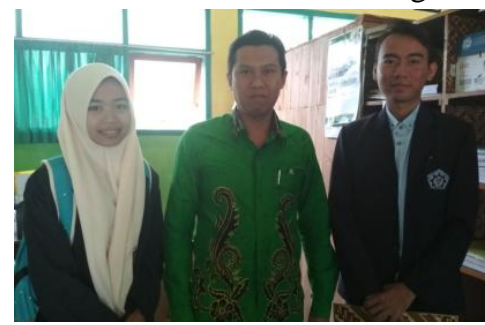

Gambar 3.Observasi dan Wawancara dengan Ketua RT Keluarahan Bulusan

2. Forum Diskusi dan Menentukan Masalah pada Lingkungan Sekitar 
Pada tanggal 16 Agustus 2018 pukul 19.00 - 21.00 WIB diadakan Forum Diskusi dan Sosialisasi Program PKM dilaksanakan di Mushola dekat Rumah Bapak RT Fatkhul Bahri. Tujuan diadakan Forum Diskusi dan Sosialisasi ini untuk menggali informasi tentang permasalahan yang ada di daerah Kelurahan Bulusan. Hasil dari forum diskusi tersebut terdapat beberapa permasalah yang dihadapi oleh warga Kelurahan Bulusan khususnya sekitar Eks TPSA Bulusan, yaitu sampah plastik, pencemaran air, dan belum adanya jenis tanaman yang cocok untuk lahan tandus. agar masyarakat mengetahui program peneliti yaitu mengolah sampah menjadi paving, serta menyamakan persepsi masyarakat tentang pemahaman Program PKM. Gambar 4 menunjukkan Dokumentasi Diskusi dan Persamaan Persepsi Kegiatan PKM di TPSA Bulusan tentang Program Ompimpah.

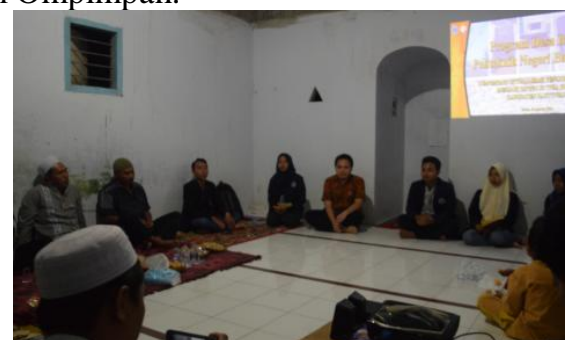

Gambar 4. Diskusi dan Persamaan Persepsi Kegiatan PKM

3. Menentukan Pokok Permasalahan yang Terjadi dan Mengangkat sebagai Judul Kegiatan.

Setelah proses diskusi, didapatkan beberapa masalah yang ada dan sedang dihadapi oleh masyarakat. Dalam hal ini, diambil tiga masalah yang sifatnya paling urgent untuk segera dicari cara pemecahannya. Permasalahan tersebut adalah sampah plastik, pencemaran air, dan belum adanya jenis tanaman yang cocok untuk lahan tandus. Dalam Kegiatan ini, tim PKM mengambil masalah mengenai sampah plastik yang memiliki waktu lama untuk terurai. Dengan demikian, program ini mengangkat tema lingkungan berjudul "(OMPIMPAH) Optimalisasi Pengolahan Sampah menjadi Paving di TPSA Bulusan Kabupaten Banyuwangi”.

\section{Brainstorming}

Brainstorming adalah sebuah perencanaan atau kegiatan yang digunakan untuk menampung kreatifitas kelompok dan biasanya digunakan untuk menjaring ide-ide inovatif yang diperlukan. Adanya brainstorming dimaksudkan untuk mengumpulkan ide-ide kreatif sebanyak mungkin didalam suatu kelompok. Adapun brainstorming dari program ini adalah membuat produk inovatif berupa paving yang berbahan dasar sampah plastik. Sampah plastik umumnya memiliki waktu urai yang sangat lama, jika tidak dimanfaatkan untuk diolah menjadi sesuatu yang bermanfaat maka hal ini akan mengganggu lingkungan. Adanya pengolahan sampah plastik ini mejadi paving secara tidak langsung akan mengurangi dampak pencemaran lingkungan akibat sampah plastik dan mampu menambah pendapatan warga sasaran.

5. Mewujudkan Ide menjadi Sebuah Produk Tepat Guna Jika ide kreatif dan inovatif telah berhasil ditemukan dan dirasa layak, maka langkah selanjutnya adalah mewujudkan ide tersebut menjadi sebuah teknologi tepat guna. Harapan adanya teknologi tersebut dapat mengatasi problematika yang sedang dihadapi oleh masyarakat khususnya warga sekitar Eks TPSA Bulusan.

6. Implementasi Produk

Langkah ini dapat dikatakan sebagai inti dari sebuah Kegiatan. Indikator keberhasilan dari program ini adalah adanya manfaat yang dirasakan masyarakat sekitar atas produk yang dihasilkan. Kegiatan yang baik merupakan implementasi program juga berhasil dilapangan, tidak hanya diatas kertas putih.

7. Evaluasi

Kegiatan evaluasi merupakan proses yang sistematis. Proses sistematis adalah kegiatan yang terencana dan dilakukan secara berkesinambungan, mulai dari awal kegiatan sampai program dikatakan selesai. Selain itu, evaluasi dilakukan untuk mengetahui progres yang telah dilakukan.

\subsection{Pengolahan Sampah Plastik Menjadi Bentuk Paving}

Sebelum membuat paving berbahan dasar plastik bekas, hal yang perlu dilakukan pertama kali yaitu persiapan bahan dan peralatan untuk membuat satu bentuk paving ditunjukkan pada Tabel 4.1

Tabel 4.1 Bahan dan Peralatan

\begin{tabular}{|l|l|c|c|}
\hline No & \multicolumn{1}{|c|}{ Komposisi } & Qty & Satuan \\
\hline 1. & Sampah plastik & 3 & $\mathrm{Kg}$ \\
\hline 2. & Oli bekas & 200 & $\mathrm{ml}$ \\
\hline 3. & Sekam bakar & 500 & $\mathrm{gr}$ \\
\hline 4. & Semen & 100 & $\mathrm{gr}$ \\
\hline 5. & Air & 1 & ember \\
\hline No & \multicolumn{1}{|c|}{ Peralatan } & Qty & Satuan \\
\hline 1. & Tungku darurat & 1 & bh \\
\hline 2. & Serbuk gergaji kayu & 1 & bh \\
\hline 3. & Kayu bakar & 1 & bh \\
\hline 4. & Korek api & 1 & bh \\
\hline 5. & Wajan & 1 & bh \\
\hline
\end{tabular}




\begin{tabular}{|l|l|c|c|}
\hline & penggorengan & & \\
\hline 6. & Sotel & 1 & bh \\
\hline 7. & Ember & 1 & bh \\
\hline 8. & Cetakan paving & 1 & bh \\
\hline 9. & Pres paving & 1 & bh \\
\hline
\end{tabular}

Teknik atau cara dalam pembuatan paving berbahan dasar plastik bekas ditunjukkan pada Tabel 4.2

Tabel 4.2 Tahapan Pembuatan Paving Plastik

\begin{tabular}{ll}
\hline No. & Tahapan \\
\hline 1. & Siapkan tungku darurat \\
& berbahan bakar dari \\
& serbuk gergaji kayu. \\
& Serbuk gergaji kayu \\
& dipilih sebagai bahan \\
bakar perapian \\
dikarenakan mampu \\
memberikan panas yang \\
tahan lama dibanding \\
dengan kayu batangan.
\end{tabular}

2. Setelah tungku menyala, letakkan wajan penggorengan dan masukkan oli bekas 200 $\mathrm{ml}$. Oli bekas berfungsi sebagai pengganti minyak goring dalam penggorengan makanan pada umumnya serta mempercepat pelelehan plastik.

Gambar 5.Tungku Darurat

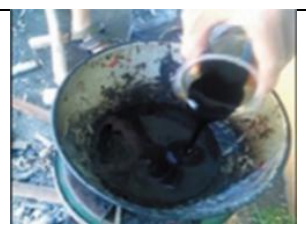

Gambar 6. Memasukkan Oli Bekas

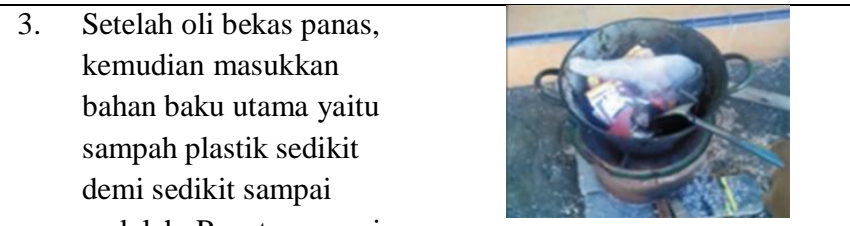
meleleh. Penutupan wajan penggorengan juga diperlukan untuk

Gambar 7.Memasukkan Sampah Plastik mempertahankan panas wajan sehingga proses pelelehannya semakin cepat. Gunakan sotel untuk mengaduk adonan. dalam pembuatan 1 paving, dibutuhkan sampah plastik sebanyak satu sampah plastik merah yang penuh atau $3 \mathrm{~kg}$.

4. Jika sampah plastik sudah meleleh seluruhnya, hal yang dilakukan yaitu dengan mencampur sekam bakar sebanyak 500 gram dan semen sebanyak 100 gram. Pencampuran sekam Gambar 8. Memasukkan Sekam bakar berfungsi sebagai media penguat lelehan sampah plastik.

Sedangkan pencampuran semen berfungsi sebagai peredam panas yang berlebih dalam paving ketika diaplikasikan pada jalan.
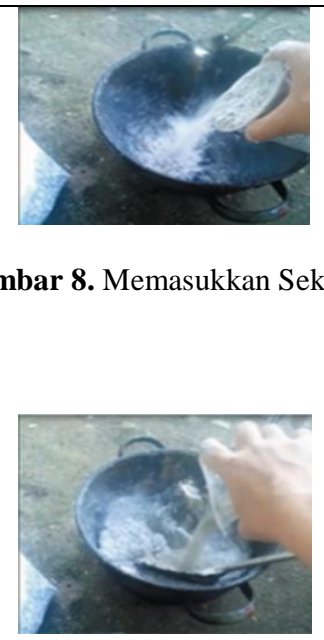

Gambar 9.Memasukkan Semen

5. Apabila setelah pencampuran adonan dengan sekam serta semen mengalami pengerasan, dapat dilakukan pemanasan kembali agar adonan tercampur rata.

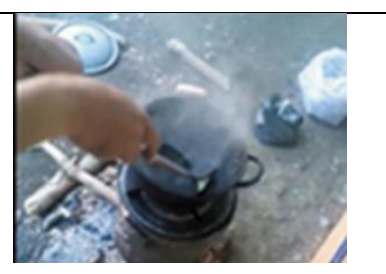

Gambar 10Pemanasan Kembali 


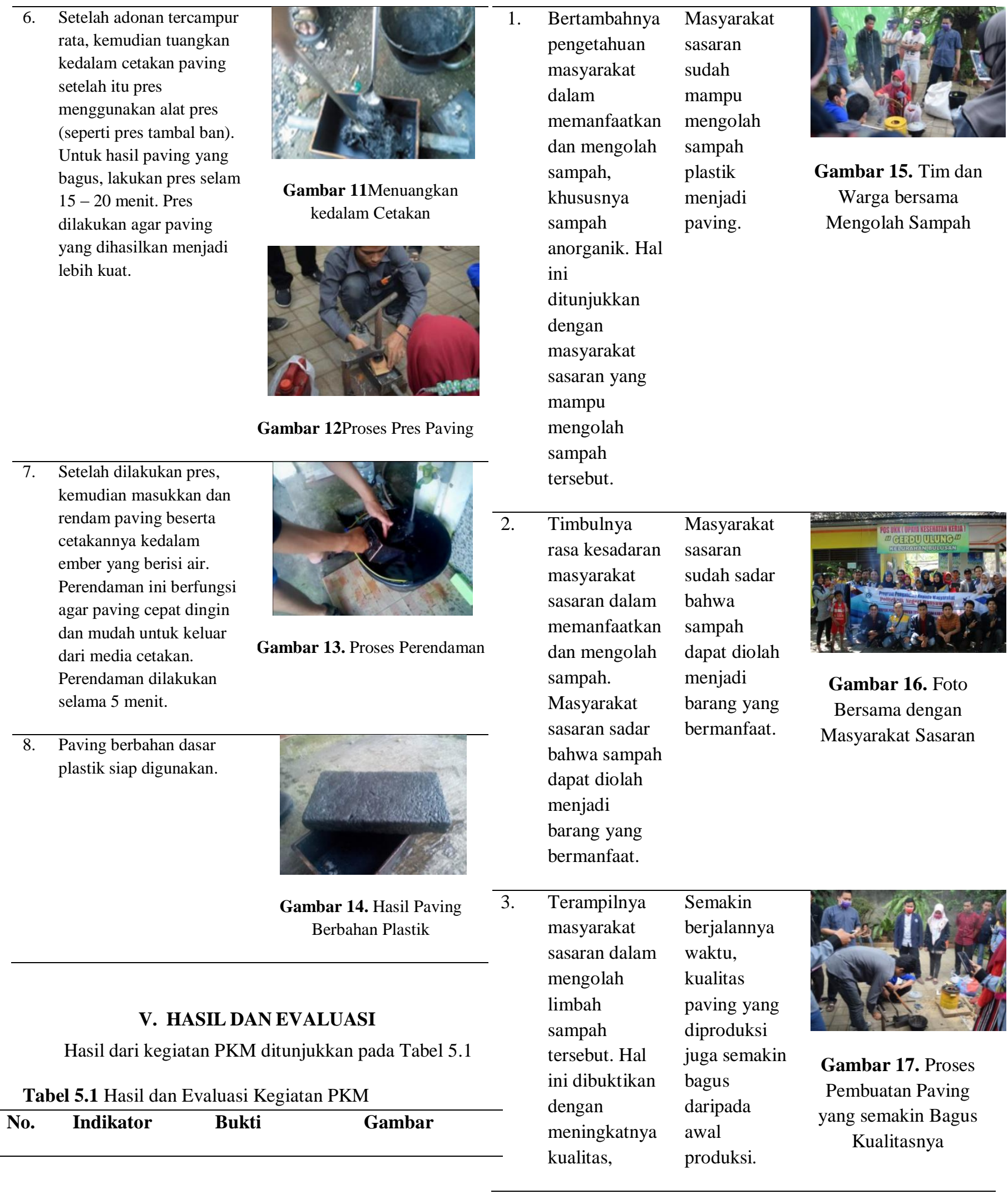




\begin{tabular}{|c|c|c|c|}
\hline & $\begin{array}{l}\text { variasi, dan } \\
\text { jumlah dalam } \\
\text { produksi } \\
\text { setiap } \\
\text { periodenya. }\end{array}$ & & \\
\hline 4. & $\begin{array}{l}\text { Adanya } \\
\text { perubahan } \\
\text { fisik yang } \\
\text { terjadi pada } \\
\text { masyarakat } \\
\text { sekitar. Hal ini } \\
\text { ditunjukkan } \\
\text { dengan mulai } \\
\text { menerima dan } \\
\text { mengetahui } \\
\text { dampak yang } \\
\text { baik atas } \\
\text { program ini. }\end{array}$ & $\begin{array}{l}\text { Sebagian } \\
\text { besar } \\
\text { masyarakat } \\
\text { sasaran } \\
\text { mulai } \\
\text { menerima } \\
\text { dan } \\
\text { mengetahui } \\
\text { dampak yang } \\
\text { baik atas } \\
\text { program ini. }\end{array}$ & $\begin{array}{c}\text { Gambar 18. Warga } \\
\text { Berdikusi dalam } \\
\text { Memecahkan } \\
\text { Permasalahan } \\
\text { Lingkungan }\end{array}$ \\
\hline 5. & $\begin{array}{l}\text { Terjalinnya } \\
\text { kemitraan } \\
\text { dengan } \\
\text { berbagai } \\
\text { pihak. Selama } \\
\text { masa binaan, } \\
\text { akan menjalin } \\
\text { mitra dengan } \\
\text { pihak yang } \\
\text { memiliki } \\
\text { peralatan } \\
\text { dalam } \\
\text { menunjang } \\
\text { pengolahan } \\
\text { sampah ini. } \\
\text { Selain itu juga } \\
\text { menjalin mitra } \\
\text { dengan } \\
\text { UMKM } \\
\text { Banyuwangi } \\
\text { guna } \\
\text { memasarkan } \\
\text { produk. } \\
\text { Setelah masa } \\
\text { pembinaan, } \\
\text { mitra yang }\end{array}$ & $\begin{array}{l}\text { Sudah } \\
\text { terjalinnya } \\
\text { kemitraan } \\
\text { dengan } \\
\text { Dinas } \\
\text { Lingkungan } \\
\text { Hidup } \\
\text { Kabupaten } \\
\text { Banyuwangi } \\
\text { dalam } \\
\text { pengolahan } \\
\text { sampah. } \\
\text { Masih } \\
\text { menunggu } \\
\text { waktu yang } \\
\text { tepat untuk } \\
\text { menjalin } \\
\text { kemitraan } \\
\text { dengan } \\
\text { UMKM } \\
\text { Kabupaten } \\
\text { Banyuwangi, } \\
\text { waktu yang } \\
\text { peneliti bidik } \\
\text { ketika } \\
\text { adanya }\end{array}$ & $\begin{array}{c}\text { Gambar } 19 . \\
\text { Kemitraan dengan } \\
\text { DLH }\end{array}$ \\
\hline
\end{tabular}

$\begin{array}{ll}\text { terjalin } & \text { pameran } \\ \text { semakin } & \text { produk } \\ \text { banyak guna } & \text { inovatif, } \\ \text { memperlancar } & \text { peneliti } \\ \text { program yang } & \text { mengajukan } \\ \text { sudah ada. } & \text { produk ini } \\ & \text { untuk } \\ & \text { mengikuti } \\ & \text { pameran agar } \\ & \text { dapat dikenal } \\ & \text { khalayak } \\ & \text { umum. }\end{array}$

\section{VI.KESIMPULAN}

Dengan diadakannya Program PKM ini dapat membantu mengurangi kuantitas volume sampah yang ada di TPSA Bulusan dan meningkatkan perekonomian masyarakat sekitar terutama masyarakat sasaran sekitar TPSA Bulusan. Sebagian besar masyarakat sasaran mulai menerima dan mengetahui dampak yang baik atas program ini. Masyarakat sasaran juga sudah mampu mengolah sampah plastik menjadi paving dan sudah sadar bahwa sampah dapat diolah menjadi barang yang bermanfaat. Semakin berjalannya waktu, kualitas paving yang diproduksi juga semakin bagus daripada awal produksi, serta sudah terjalinnya kemitraan dengan Dinas Lingkungan Hidup Kabupaten Banyuwangi dalam pengolahan sampah dan satu kemitraan dengan Bapak Fatkhul Bahri selaku RT Bulusan. Diharapkan setelah adanya kegiatan dari Program PKM ini, masyarakat desa Bulusan dapat mengelola sampah dengan optimal agar dapat menghasilkan suatu produk paving yang berkualitas dari sampah sehingga bisa menambah pemasukan bagi masyarakat sekitar

\section{UCAPAN TERIMA KASIH}

Ucapan terimakasih disampaikan kepada tim pengabdian kepada masyarakat yang telah berjuang untuk mengabdi. Dan untuk Politeknik Negeri Banyuwangi yang memfasilitasi kegiatan PKM Bulusan melalui Program Ompimpah ini.

\section{DAFTAR PUSTAKA}


Jurnal Pengabdian Masyarakat J-DINAMIKA, Vol. 3, No. 2, Desember 2018,

P-ISSN: 2503-1031, E-ISSN: 2503-1112

[1] Bakhtiar, Muhammad Yannefri, 2010. Posdaya: Sebuah Implmenetasi Paradigma Bottom Up Planning dan Pembangunan Berbasis Masyarakat.

[2] Prasetyo PEA, 2015, Perancangan Mesin Penghancur Sampah Plastik Dengan Kapasitas 250 kg/jam. Aneka Mesin, Jakarta.

[3] Saleh Ahmad, dkk. 2013. Pengembangan Modal Sosial dan Kewirausahaan Sosial Melalui Posdaya

[4] Umar, H., 2003. Studi Kelayakan Bisnis, PT. Gramedia, Jakarta

[5] Wahyono, A., Arifianto, A.S., Wahyono, N.D. and Riskiawan, H.Y., 2017. Prospek Ekonomi Kebijakan Pemanfaatan Produktifitas Lahan Tidur Untuk Pengembangan Porangdan Jamur Tiramdi Jawa Timur. CAKRAWALA, 11(2), pp.171-180.

[6] Setyohadi, D.P.S. and Riskiawan, H.Y., 2014. Pendataan Hasil Produksi Pisang Berbasis Keruangan di Kabupaten Lumajang. Jurnal Teknologi Informasi dan Terapan, 1(2). 